\title{
Beyond Being There, for "All of Us": Exploring Webconferencing and Mobile Remote Presence Devices for Accessible Global Governance
}

\author{
Derrick L. Cogburn \\ American University \\ dcogburn@american.edu
}

\begin{abstract}
United Nations efforts to support multistakeholder global governance continue to lag for persons with disabilities. Given the expense of face-to-face meetings, accessible ICTs could play an important role, enabling remote participation. However, what types of collaboration technologies best meet UN goals and those of remote participants? This study compares use of webconferencing technologies to mobile remote presence devices (MRP) in a UN conference in Mexico addressing Disaster Risk Reduction. It takes an exploratory action research approach working with UNISDR and the Disabilityinclusive Disaster Risk Reduction (DiDRR) Network \#AllofUs to convene four remote hubs (Suva, Dhaka, Geneva, DC), each controlling their own MRP in Cancun and having access to the webconference, along with other remote participants around the world. We ask: Which technologies best support required conference tasks; and what social and technological challenges arise with their use? Under the conditions of this study, both technologies appeared to be complementary.
\end{abstract}

\section{Introduction}

From the time of its founding in 1945, the United Nations has attempted to provide opportunities for structured civil society engagement in its processes.[26][61] However, the multiple meetings required to engage effectively in any specific UN process are long, complex, and take place in diverse locations, from UN Headquarters in New York City, to the Palais des Nations in Geneva, Switzerland, to host countries and venues around the world. Even when invited, or allowed to attend these week-long or multi-week events, participating face-to-face can be time consuming and expensive, costing upwards of $\$ 5,000$ per person (including transportation, housing, and food). Our previous research on accessible global governance has shown that these expenses are often exacerbated for persons with disabilities, who often need to travel with personal assistants and/or interpreters [26][60]. Given these expenses, information and communication technologies (ICTs) could play a critically important role enabling remote participation for all civil society participants in these multistakeholder global governance processes, but particularly for persons with disabilities. However, what types of ICTs best meet the needs of UN conference organizers, as well as those of remote participants? One increasingly popular technology used for these purposes is webconferencing, with several UN conferences, such as the Internet Governance Forum (IGF) attempting to integrate these technologies into their infrastructure. While webconferencing opens tremendous opportunities for remote participation, it has its own limitations, and newer technologies could offer alternatives. This study seeks to better understand the role ICTs can play in enhancing remote participation in global governance for persons with disabilities, by comparing the use of webconferencing technologies to mobile remote presence devices (MRPs) in a UN conference in Mexico focused on Disaster Risk Reduction (DRR). It takes an action research approach and works in collaboration with the UNISDR to convene four remote hubs populated by disability advocates (Geneva, DC, Fiji, Dhaka), each piloting their own MRP in Mexico and having access to the accessible webconference, along with other remote participants around the world. They used the hashtag \#AllofUS to reflect their goals for disability inclusion in DRR.

\section{Literature Review}

\subsection{Virtual Presence}

In 1992 Jim Hollan and Scott Stornetta published a paper entitled "Beyond Being There" for CHI, the ACM conference on Computer Human Interaction. This highly influential paper argued that much of the research community studying geographically 
distributed collaboration had been driven by the overriding belief promoted by the telecommunications industry that the goal of distributed collaboration tools was to imitate face-to-face communication. They argued that the primacy of this belief led to an unhealthy focus on high end videoconferencing systems, and one might add subsequently to collaboration tools marketed as "teleprescence systems." For Hollan and Stornetta, this approach was misguided and contributed to many fruitful research avenues not being explored sufficiently. Instead, they promoted the idea of trying to go "beyond being there," to look at ways that researchers could use communication needs, media, and mechanisms as a framework for exploring how distributed collaboration tools may address each one of these areas, and create platforms for collaboration that were sought after and exploited by users for their own right; not because they imitated "face-to-face" communication.

This article influenced much of the work of the U.S. National Science Foundation (NSF) on Virtual Organizations [8] and much of the work of our own research lab. We understood and evaluated these two divergent streams of socio-technical approaches to supporting geographically distributed collaboration. The high-end telepresence systems marketed by such companies as Cisco, Tandberg, Polycom, and others; compared to the emerging class of technology known as webconferencing. This latter approach, focused much more on providing the infrastructure to support those three communication needs, rather than trying to replicate or imitate "being there." In our research, we put webconferencing through many important trials, and as the technologies matured, their efficiency and effectiveness improved tremendously. [26][61].

Nonetheless, in recent years, there has been substantial innovation in the class of technology known as Mobile Remote Presence (MRP) devices. Although there are a wide variety of MRP devices available on the market, some commercially over the counter (e.g. Double), others custom designed (QB, Texai, VGo), and still others in prototype in the lab or in field trials (TOURBOT). They all have many common features. They almost all have some form of wheeled mobility capabilities, that allows the device to be controlled by a remote pilot (usually, connected from anywhere in the world with Internet access). Another common feature is a "head" unit, that allows video of the user to be seen by local persons, and in almost all cases, interactive audio through a local microphone and speaker. These systems are operated by a remote user piloting the MRP device in a local environment using the open Internet

There is a voluminous and growing literature on MRPs.[2] Much of this literature has been segmented into the following categories: (1) design related studies, focusing on human computer interaction and computer supported collaborative work $[7][17][18][20][21][24][45][46][47] ; \quad$ (2) workplace evaluations, in different industries [4][9][29]; (3) medical environments [3][6][10][15][40][41][43]; (4) educational settings [12]; and (5) social communities (e.g. aging and museum communities) [16][50]. This collection of studies has identified a relatively common set of features of MRPs, and varying perceptions of their efficiency and effectiveness.

The design related studies highlight areas such as: quality of communication; attitudes and acceptance measures; societal and ethical issues; and technologyrelated measures (e.g. interface design, autonomy, and communication channel robustness) [2].

In terms of domain-specific uses of MRPs in office environments, the literature points to practices such as: telecommuting; visiting local co-workers, participating in formal and perhaps more importantly, informal or casual meetings; in the health care environment, bedside rounds by personal physicians, expert "teleconsulting" and "telementoring," postoperative care in the home; in the aging environment, uses include: health surveillance, data collection, emergency alert system; in educational settings, uses include students attending classes remotely; teachers delivering lectures from a remote location; and in communities, they have been used to foster increased social connectivity, increased communication, and ability to tour remote facilities like museum exhibits.

The existing literature also identifies ways in which the user community tries to humanize the robots. Some examples include MRPs that have human faces and features built into an avatar, while others include simply adding a shirt or other accessory.

However, while some of the articles focus on aging and elder populations, it appears that none of the existing studies have been conducted with a focus on persons with disabilities and their specific needs. This current study addresses that oversight, with a comparative study of MRPs and webconferencing technologies to enable remote participation for persons with disabilities in UN conferences.

\subsection{Cyberinfrastructure to Support Persons with Disabilities}

The founding charter of the United Nations starts off with "We the Peoples of the United Nations...". Since its founding in 1945, the UN has attempted to identify mechanisms for non-state actors to get involved in the work of this essentially member-state organization. Starting in 1946, United Nations Associations (UNAs) and the World Federation of 
United Nations Associations (WFUNA) have tried to provide access for citizens of UN member states to access the UN.[21][61] At the Earth Summit in Rio de Janeiro in 1992, the "Major Groups" Framework was adopted, which gives special access to UN processes for nine stakeholders, including: (1) women; (2) children and youth; (3) farmers; (4) indigenous peoples; (5) NGOs; (6) trade unions; (7) local authorities; (8) science and technology; and (9) business and industry. This Major Groups framework ignores the more than 1 billion persons in the world living with some form of disability. [38]

Much of our research over the past several years has attempted to rectify this oversight. One of the major efforts was in the $3^{\text {rd }}$ UN World Conference on Disaster Risk Reduction (3WCDRR), held in 2015 in Sendai, Japan. With substantial support from The Nippon Foundation, the Sendai Conference was one of the most accessible conferences in history, from the perspective of transportation, accommodation, information, and physical accessibility, and led to the adoption of the Sendai Framework for Disaster Risk Reduction. [44] Understanding the needs of persons with disabilities in disaster risk management was critical, and in December 2015, the Dhaka Declaration on Disability and Disaster Risk Management was adopted. [11] These documents lay the foundation for disability-inclusive disaster risk reduction (DiDRR).

\subsection{Global Governance and UN Conferences}

But with these increasing openings for civil society and non-state stakeholders to get more involved, is it possible for persons with disabilities to take advantage of these openings? We have studied the social, political, technological, and economic factors that limit the potential for persons with disabilities to take advantage of these opportunities. This includes the activities before, during, and after the conferences and engage in what is called "Conference Diplomacy."

\subsection{Accessibility, ICTs, and Collaboration}

Global virtual teams, and transnational advocacy networks, supported by accessible information and communication technologies are some of the institutional mechanisms that may be able to enhance the potential of this important community.

Some of our previous work has focused on the "collaboratory" approach, and worked to integrate content management systems (CMS) to support asynchronous collaboration amongst this community, with accessible webconferencing tools integrated into these networks to support their strategic engagement.
Previously, we reported on our work to enhance the disability community's engagement in Habit III and the UN Conference on Housing and Sustainable Urban Development, and the development and adoption of the New Urban Agenda in October 2017.In this study, we build on those lessons, and apply them to the attempts by the disability community to engage in the follow-up and implementation of the Sendai Conference in the 2017 Global Platform for Disaster Risk Reduction (GP2017). For this study, we have focused on a comparative analysis of webconferencing technologies and MRP systems.

\section{Exploratory Framework}

Based on this literature, the exploratory framework for this study has five key areas: (1) tasks required or desired to be performed by remote participants; (2) technical issues with using webconferencing and MRPs; (3) accessibility and interface; (4) evaluation, both by remote users in terms of social presence and information richness; and (5) impressions of local participants. These issues are likely to be related to satisfaction with the specific remote collaboration technology on the part of both the remote participants, local participants, and conference organizers.

\section{Research Questions}

Out of this framework, we ask three overarching research questions, and nine subsidiary-questions:

RQ1. Which collaboration technology, webconferencing or MRPs, best supports conference tasks for remote participation in preparation for, during, and after GP2017?

SQ1.1 What conference tasks are required or desired by conference organizers of remote participants?

SQ1.2 What conference tasks are desired by remote participants?

SQ 1.3 Does webconferencing or MRPs enable these tasks more efficiently?

RQ2. What social challenges and opportunities arise with the use of webconferencing and MRPs for remote participation?

SQ2.1how do local conference participants react to the MRP?

SQ2.2 How do remote users evaluate the social presence and information richness provided by the webconference and MRP? SQ2.3 How to local users evaluate the social presence and information richness provided by the webconference and MRPs? 
RQ3. What technological challenges and opportunities arise in the use of webconferencing and MRPs for remote participation?

SQ3.1 What technology infrastructure is required for webconferencing and MRPs?

SQ3.2 What level of accessibility for PWDs exists in webconferencing and MRPs?

SQ3.3. How comfortable are users with the UI of the webconference and MRP systems?

\section{Methodology}

This study is structured as action research [55][56][57], designed to help understand which ICTs can best support accessible remote participation for large international conferences. Participants in the study include advocates from the global disability community engaging in Global Platform 2017 (GP2017), held from 22-26 May 2017 in Cancun, Mexico. GP2017 is the first follow-up conference to focus on implementation of the Sendai Framework. In this study, we will have two broad groups of participants, those "local participants" on the ground in Cancun registered to attend GP2017 and "remote participants" who will be attending the conference virtually, either individually or in one of four "remote hubs" located in either: (1) Washington, DC; (2) Brussels, Belgium; (3) Dhaka, Bangladesh; or (4) Suva, Fiji. In total, 66 individual persons participated remotely during GP2017, with 31 piloting the robot.

\subsection{Webconferencing Infrastructure}

The webconferencing infrastructure we used for the study is Blackboard Collaborate Ultra (http://blackboard.com/). This is the newest version of Blackboard Collaborate, and uses HTML5 and moves away from the java-based infrastructure of its now Classic edition, and its concomitant limitations. This choice of webconferencing tool was based in part on our longstanding use of this technology for our global accessible master's program; but also on our prior service on the accessibility task force for Collaborate and for its predecessor Elluminate. Collaborate Ultra works in low bandwidth environments, and is based on a philosophy of "leave no user behind. Collaborate also has a free mobile application to enable active participation via smart phones and tablets.

\subsection{Mobile Remote Presence Robots}

For our Mobile Remote Presence (MRP) devices, our robots, we chose the Double2 product, by Double Robotics (http://doublerobotics.com/). Based in
Burlingame, California, Double Robotics started shipping in 2013. The Double MRP can be piloted from a computer using a Chrome browser, or via an iOS mobile app for iPhones and iPads. It can be elevated by the remote pilot from a low "sitting" height of 41 " to a low "standing" high of 60 ". The pilot may also control the speaker volume, camera angle, and invite up to five additional "riders" on the Double, sort of like a virtual side car. This Double2 product has some additional advantages, included a "power drive" feature that lets it go up to $80 \%$ faster, from $1 \mathrm{mph}$ (80 feet per second) to $1.8 \mathrm{mph}$. It also has end-to-end 128-bit encryption and 720p HD video.

\subsection{Phase I: Before GP2017}

Phase I took place before the Global Platform 2017 (GP2017), which begins on 22 May 2017. During Phase I, we focused on a baseline assessment of collaboration readiness, including trust, networking, culture, organizational infrastructure and ICT expertise. Our primary data collection was through observations of virtual meetings, and email exchanges with registered participants of each of the four remote hubs (DC, Brussels, Dhaka, and Fiji), and during our preparatory meetings with remote hub organizers.

\subsection{Phase II: During GP2017}

Phase II took place during the actual Global Platform 2017 conference in Cancun, Mexico, from 22-26 May 2017. During this phase, we conducted individual interviews with remote hub participants, particularly those that drove the robot. We also conducted brief focus groups with remote hub participants to assess their collective experience.

We also observed the participants of GP2017 on the ground in Cancun to assess their experiences with seeing and engaging with the MRPs and webconferencing participants during the conference.

\subsection{Phase III: After GP2017}

After GP2017, UNISDR sent a follow-up survey to all registered participants and attendees of remote hubs for a post-test assessment of their experiences with the remote participation. Results are not reported here.

\section{Findings}

Our preliminary findings are organized around our three primary research questions: (1) Which of the two collaboration technologies, webconferencing and MRPs, best supports the needs for remote participation 
in GP2017? (2) What social challenges arise with the use of the two collaboration technologies in GP2017? (3) What technological challenges arise from the use of the two collaboration technologies in GP2017?

\subsection{Support for Remote Participation Goals}

Our initial research question asks which collaboration technology, webconferencing or MRPs, best supports conference tasks for remote participation in preparation for, during, and after GP2017? Since the Global Platform is organized by UNISDR the United Nations Office for Disaster Risk Reduction, we first examined their goals for remote participation.

6.1.1. Goals of the Conference Organizer. As the first UN follow-up meeting to the historic Sendai Conference, and since Sendai was a watershed in international conference accessibility, GP2017 had accessibility at the forefront of its planning and negotiations with the host country, the government of Mexico, and the city of Cancun. Like Sendai, The Nippon Foundation provided substantial financial support to the United Nations to facilitate and stimulate a focus on accessibility. It also provided support to the Institute on Disability and Public Policy (IDPP) at American University, to provide support to the United Nations and to the global disability community. This collaboration, reflected in the Accessibility Statement for the conference (http://www .unisdr.org/conferences/2017/globalplatf orm/en/accessibility), helps to reflect the multiple goals of the conference organizers for remote participation. The wanted the conference itself to be "accessible to persons with disabilities." [54] It cited several UN General Assembly resolutions which:

urged the United Nations system to make a concerted effort to integrate disability into its work and encouraged the Inter Agency Support Group on the Convention on the Rights of Persons with Disabilities to work to ensure that development programmes, including Sustainable Development Goals policies, processes and mechanisms, are inclusive of and accessible to persons with disabilities. [51][52][53]

Part of the commitment focused on physical accessibility to the conference facilities, accessible documentation, logistics, and to providing sign language interpretation in International Sign within the conference plenary and special sessions to ensure a "disability-inclusive approach to disaster risk reduction." [54] The commitment also included working with IDPP to provide remote participation. GP2017 remote participation goals were designed: ...to increase the opportunities for participation in the 2017 Global Platform from around the world, multiple opportunities for accessible remote participation will be offered. The overall goal is to increase access to the conference for remote participants around the world who would otherwise be unable to attend.[55]

UNISDR wanted remote participants to be able to attend formal plenary and working sessions, as well as side-events, which were relatively less formal. They also wanted remote participates to be able to "experience" the conference, including the coffee breaks, hallway conversations, visiting the Marketplace, an exposition of booths and organizations, and to have the freedom of movement around the conference. UNISDR had learned about MRP devices and the etiquette associated with piloting robots in office environments. He said he "immediately recognized the potential of these robots for use at an international conference like the GP2017.’[59]

While the robots addressed some of the UNISDR goals for remote participation, researchers at IDPP felt they would not meet them completely. In collaboration, UNISDR and IDPP agreed to broaden the collaboration technologies available for remote participation to include accessible webconferencing, and to explore the relationship between these technologies and effective participation by the global disability community. Also, since UNISDR had the goal of stimulating participation of targeted disability communities, IDPP introduced the idea of "remote hubs", pioneered in Internet governance, and three were selected by UNISDR, which were Suva, Fiji; Dhaka, Bangladesh, and Brussels, Belgium. A fourth remote hub was selected by IDPP as Washington, D.C. Funds provided by The Nippon Foundation were available to support each remote hub, which was assigned a robot, and provided with pre-conference training on accessible webconferencing infrastructure, and on piloting the robot.

6.1.2. Participants Objectives. The objectives and tasks desired by remote participants were a little harder to assess. From our initial interviews, it appeared that participants in the remote hubs were interested in broadening their knowledge of disability inclusive disaster risk reduction, and since they could not participate in person, they wanted to gain as much experience and information as possible. They also appeared to appreciate the idea of experiencing these new collaboration technologies in a collective, social, environment, rather than doing so alone.

6.1.3 Comparison of Collaboration Tools. Which ICTs addressed the collaboration goals better? Under 
the conditions of this study, it seems both technologies allowed remote participants to "attend" formal plenary sessions, offering advantages and disadvantages. Accessible webconferencing allows a near unlimited number of participants to attend the formal plenary and working sessions, either collectively by gathering in a "remote hub" where the webconference can be projected on a screen, with microphones and a camera to capture the participants. They can discuss the proceedings together, and raise joint questions in the chat box or on video/audio. The robot however, allows only 1 person at a time to pilot the robot, and thus to make choices about which session they attend. They can add up to five additional "riders" who can go along with the robot, see the video the pilot sees (but not project their own), and speak. We accommodated up to 24 persons on all four robots at any given time.

Another positive aspect of the webconferences was the proximity to the material being presented (e.g. slides, websites, videos, etc.). The robots were always long distances from the slides (but they were receiving a view of the slides that more closely resembled the view of local audience members). Normally, webconference participants receive a very high quality view of the slides, and in most instances, can receive the high-definition video/audio feed available from conference organizers. Unfortunately, in this study, these major benefits were not realized because of a technical oversight on our part. Our team in the field did not have a video capture card to enable us to import the production feed into the webconference (we have subsequently purchased a BlackMagic UltraStudio video capture device). As a result, webconference participants in the large plenary sessions, were left with a very wide angle, long distance video image. Nonetheless, using our Blue Icicle XLR to USB converter, we captured room audio from all microphones, including podium, panel, and audience. Here, the webconference appeared to exceed the capabilities of the robots, who sometimes struggled to hear audio from plenary and working session rooms.

However, when considering the desire by UNISDR for remote participants to be able to attend informal meetings, and to be able to "experience" the conference, including the coffee breaks, hallway conversations, visiting the Marketplace, and freedom of movement around the conference, there seemed to be no contest. The MRP devices provided tremendous flexibility for the remote participants to make choices about where to go, to have numerous informal interactions, meetings, tour the marketplace and chat with people at the booths (including the disability booth where they could always meet other participants with disabilities), visit the coffee area, where they could sit informally and chat with other participants.
Both remote participation options were very ecologically friendly (no travel, less carbon footprint), and both seemed to help create a sense of community amongst the global disability community involved in the conference. UNISDR conference organizers believe that the use of these two collaboration technologies, coupled with the What'sApp group we created provided "complimentary channels" and allowed us to create a shared team experience for the disability community that was both present and absent.[60] Given the hashtag the disability community adopted for the conference \#AllofUs, this feeling was quite welcome. All the robots even wore t-shirts emblazoned with this hashtag, as well as the name of the Disability Remote Hub they represented.

\subsection{Social Challenges to Remote Participation}

Interestingly, several social challenges appeared to arise from the use of the collaboration tools, particularly the robots; as well as some unexpected opportunities. The social challenges included people stopping the robot to ask questions and take pictures as pilots were trying to navigate around the conference venue. Sometimes this became quite disruptive, as the novelty of the robots seemed to create quite a stir at the conference, almost everywhere they went. Also, some pilots did not know how to engage the speed boost option, enabling the robots to move at approximately $2 \mathrm{~km}$ per hour or walking speed. The result was some people found it difficult to "walk and talk" with the robots as they navigated the expansive conference center. Also, since many remote pilots did not know how to raise the height of the Double, they ended up talking to people at a much lower eye line than they were used to. Also, while the robots were interrupted many times by people asking-and sometimes not asking - to take their photo, most people did not realize that the robot could also take photos of them (which could have privacy implications).

One of the most interesting opportunities afforded by the robot was the chance for all four remote hubs to meet, and interact with, the new UN Deputy Secretary General, Ms. Amina Mohammed. This would not have happened on the webconference, because of its fixed nature. The robots had to all go where she was going to be, in order for them to get the opportunity to meet with her. None of these opportunities or challenges were available to the webconference only users. However, some of the unique advantages of the webconference was that some users reported it "being on in the background" as they did other things on their computer or in their office. It did not demand the kind of focused attention the robot required. 
One part of our analysis explores how local conference participants reacted to the robot. The dominant reaction included comments such as: "Wow", "That's Amazing", "Yes, that's the future", "This is so cool", "I'm so glad you're doing this," "It is so neat they can participate that way."

Like situations faced by some persons with disabilities, many conference participants tried to "help" the robots too much. While we provided local volunteers to "watch" each robot (partially for security purposes), the Double2 has a powerful algorithm for lateral stability control that uses its gyroscope and accelerometer to enable the robot to go over bumps, cables and other obstacles while staying balanced. So, in almost all cases, the robots did not need any help getting over cables, or staying balanced. But people very frequently offered it, without asking. This is a common complaint amongst the disability community, so it was interesting that these remote participants had that same experience. Also, as found in other studies, on occasion the robots appeared to have a "disruptive effect". [59] This included speaking too loudly sometimes (and not adjusting the speaker volume); moving directly in front of the panel of speakers, distracting panelist, or standing directly in front of other audience members, blocking their view. Also, it was "difficult" to cut off a robot speaker, who was over their time (although this is a difficulty of some moderators in face-to-face conferences as well; but very easy to do with webconference participants).

On balance, remote experiences were mostly positive. The robots provided exceptional affordances to project a remote user into the local space in Cancun. Many users reported feeling like they "had been to Mexico" even though they did not have to get on a plane. Seeing and hearing such joy on the faces of the remote pilots as they navigated around the expansive conference center was an incredibly enriching experience for the researchers as well.

Information richness may have been more robust on the webconferencing technologies. The audio stream was very strong and stable for every room we connected to the webconferencing for remote participation. While we have backup strategies of using Blue Snowball microphones when we cannot get access to the soundboard, the Blue Icicle XLR to USB adaptor provides exceptional sound quality. In addition to the sound, additional information richness was provided by the ability to see the real-time closed captions, the slides, websites, and videos up close, and the ability to go back and review the webconference recordings at any time. Most of these capabilities were much weaker on the robots.

\subsection{Technical Challenges to Participation}

While the overall experience of remote participation through both the webconferencing and robots was robust, there were several technological challenges as well. We have already alluded to the missing video capture device that would have enhanced the remote experience in the webconferences tremendously (as well as the subsequent recording). This could have been rectified with better preparation and our purchase of a $\$ 140$ BlackMagic UltraDesign MiniStudio. While the WiFi network was generally very strong, there were a few lacunae, where the robot sometimes stalled when transition from one $\mathrm{Wi}-\mathrm{Fi}$ router to another. Also, there was sometimes a small latency that appeared to make it difficult to communicate. Some of the biggest technological challenges we faced were with the Double itself. While this is a commercial product, it behaves in some ways as if it was a prototype. The two biggest issues were critical; (1) audio and (2) video. Our Double is equipped with an Audio Kit, which includes a speaker connected via the headphone port, which enables a much louder speaker (than on the iPad alone) and an enhanced microphone. It was also equipped with a Video Kit, which enabled a 150degree wide-angle view (although not as crisp as the native retina display on the $\mathrm{iPad}$ ), and simultaneously a downward facing camera. Both features are very nice for piloting the Double. However, the problem is they both frequently do not pair with the iPad and do not show as installed. While there is no difference to the local participant seeing the video on the iPad, when the video kit is not installed, the pilot only sees one camera view and it has a narrower (but crisper) field of vision, and no simultaneous downward facing camera (making it harder to pilot). However, the bigger problem is that the Double does not charge the iPad when the video kit does not show as installed. Similarly, when the audio kit does not show as installed, the speaker does not work and the audio volume is limited to that of the iPad. In contrast, the webconferencing was relatively problem free, except for the missing video capture card, which would have enhanced the participant experience.

UNISDR worked with the Mexican government to ensure the Wi-Fi network was sufficient to support the Doubles. The average connection speed was $\approx 40$ Mbps, with a saturation point on Wednesday noon, with 3500 devices connected simultaneously. On Friday when with fewer people connected, network speeds were as high as $120 \mathrm{Mbps}$.[59]

In terms of accessibility for persons with disabilities, here there is again no contest, but it is the webconferencing tools that come out ahead. 
Blackboard Collaborate Ultra is one of, if not the, most accessible webconferencing platforms on the market (full disclosure the author served on the accessibility task force for Collaborate and its predecessor Elluminate). In addition, remote closed captioning can be easily scheduled and integrated. One remote user said: "The tool was quite easy to access and did not require an excessive amount of connectivity or adjustments. Indeed most of the people from the four corners of the world were able to connect with video and audio to discuss in a much easier "real time effect" than other means such as Skype."

In contrast, the web-based interface to access the Double is not accessible by a screen reader. One of our speakers who was blind, was scheduled to speak from the robot during our Working Session, was unable to connect (even though he could connect during tests).

Overall, users seemed comfortable with both the web-based interface on the Chrome browser, and the iOS app. For nearly all users it seemed easy to navigate the app, and although we designed a "Robot Driver's License" as a training, it was generally not necessary.

\section{Discussion}

In this study, we have explored the introduction of two types of collaboration technologies to support remote participation in global governance processes for the disability community. Summary, we need both. It is clear from our analysis that effective participation for the global disability community in GP2017 was enhanced by pairing both collaboration technologies, the webconferencing and the MPP devices. Either technology alone would not have yielded the results found in this study. The accessible webconferencing technologies laid a solid and persistent foundation for remote participation, while the robots created an excitement amongst both remote and local participants unrivaled by the webconferencing. In addition, the sense of belonging, and pride created by the pairing of both technologies, and the addition of the WhatsApp messaging group, helped to forge strong bonds amongst the geographically distributed network.

\section{Limitations}

As with any research study, this project has important limitations. As a quasi-experimental field study, we have been unable to randomly assign participants to each group. Also, there is no strict selection of participants, nor have we filtered which participants in each remote hub would be able to drive the robots. We have also not been able to fully execute the survey research as planned and for this paper had to pivot to focus more on an ethnographic approach. We do have recordings of all sessions, a survey designed and approved by Institutional Review Board, and UNISDR did send a survey to all participants that included an item about interaction with the robots, and a request for further interviews. We hope to be able to capitalize on these opportunities for future research.

\section{Recommendations}

Based on this study, we have several recommendations for designing systems to enhance the remote participation of persons with disabilities in UN conferences, meetings, and events.

\subsection{Recommendations: United Nations}

The UN would benefit from systematically introducing accessible webconferencing throughout all its meetings. Enabling all persons, especially persons with disabilities, to participate remotely would make a tremendous contribution to multistakeholder global governance. This approach may begin to "normalize" participation via these means, and perhaps reduce the impact of not participating in person and "privileging" those who are able to "be there." In addition, integrating more MRPs may provide an additional opportunity to participate, but this must be done carefully to address security and privacy concerns, as well as the potential disruption caused by these devices. For example, we recently completed a study using one robot for remote participation (coupled with webconferencing again) at UN HQ for the Conference of States Parties (COSP) to the UN Convention on the Rights of Persons with Disabilities (CRPD). We believe this is the first time robots have been used like this at UN HQ.

\subsection{Recommendations: Host Countries}

The Government of Mexico did an excellent job preparing for the Global Platform 2017 and, like Sendai, made a commitment at the country level and city level (Cancun) to accessibility. They worked with UNISDR and IDPP on the technical requirements to conduct this study, and to ensure there was sufficient bandwidth to support the robots and webconferencing throughout the conference venue. Future host countries should take a similar approach.

\subsection{Recommendations: Disability Community}

These types of collaboration technologies provide tremendous opportunities for the global disability 
community. In this study, we started using the webconference technologies about eight months before GP2017 to engage DiDRRN. We recommend that the global disability community continue to explore cyberinfrastructure and accessible collaboration technologies to strengthen their capabilities as virtual organizations and networks.

\section{References}

[1] Hollan, J. and S Stornetta, "Beyond Being There", CHI'92 ACM Conference on Human Computer Interaction, 3-7 May 1992, pp. 119-125.

[2] Kristoffersson, S. C. and A. Loutfi, "A Review of Mobile Robotic Telepresence." Advances in Human-Computer Interaction. Volume 2013, Article ID 902316, Hindawi Publishing Corporation, 2013.

[3] Foerster, V. "Health Policy Advisory Committee on Technology: Technology Brief: Remote Presence Robots in Telemedicine." HealthPACT emerging health technology, July 2014

[4] Munjai, D., K.M. Tsui, H.A. Yanco, and C. Uhlik., "Essential Features of Telepresence Robots." Nd.

[5] United Nations. United Nations Plan of Action on Disaster Risk Reduction for Resilience: Towards a Riskinformed and Integrated Approach to Sustainable Development. United Nations, 2017.

[6] Thobbi, A., R. Kadam, W. Sheng, "Achieving Remote Presence Using a Humanoid Robot Controlled by a NonInvasive BCI Device.", nd.

[7] Bessas, A., A. Benalia, F. Boudjema, "Integral Sliding Mode Control for Trajectory Tracking of Wheeled Mobile Robot in Presence of Uncertainties." Journal of Control Science and Engineering. Volume 2016, Article ID 7915375, pp. 1-10

[8] National Science Foundation. Beyond Being There: A Blueprint for Advancing the Design, Development, and Evaluation of Virtual Organizations. National Science Foundation. May 2008.

[9] Chua, A.L., and S. L. Pan, "Knowledge transfer and organizational learning in IS Offshore sourcing. Omega Volume 36 (2008), pp 267-281.

[10] Nestel, D., P. Sains, C.M. Wetzel, C. Nolan, A. Tay, R.L. Kneebone, and A.W. Darzi, "Communication Skills for mobile remote presence technology in clinical interactions." Journal of Telemedicine and Telecare, Volume 13, 2007, pp 100-104.

[11] "The Dhaka Declaration on Disability and Disaster Risk Management." Dhaka Conference on Disability \& Disaster Risk Management. 12-14 December, Dhaka Bagladesh.

[12] Cha, E., Q. Sajid, and M. Matarić, "Enabling Access to K-12 Education with Mobile Remote Presence." Association for the Advancement of Artificial Intelligence. 2016.

[13] Hardin, A., M. Fuller, C. Looney, and G. Schechtman. "Participative Goal Setting in Self-Directed Global Virtual Teams: The Role of Virtual Team Efficacy in Goal Setting Effectiveness and Performance."
Proceedings of the $46^{\text {th }}$ Hawaii International Conference on System Sciences, 2013.

[14] Herbsleb, J.D., "Global Software Engineering: The Future of Socio-Technical Coordination." Future of Software Engineering, 07. 2007.

[15] Mendez, I., M.C. Van den Hof. "Mobile remotepresence devises for point-of-care health care delivery." Canadian Medical Association Journal, November 19, 2013. Volume 185: Issue 17, pp. 1512-1516.

[16] Beer, J.M., L. Takayama, "Mobile Remote Presence Systems for Older Adults: Acceptance, Benefits, and Concerns." Proceedings of Human-Robot Interaction Conference: HRI 2011. Association of Computing Machinery. Lausanne, Switzerland, pp 19-26.

[17] Takayama, L., and J. Go, "Mixing Metaphors in Mobile Remote Presence." Proceedings of Computer Supported Cooperative Work, 2012, Seattle, Wash. pp. 495-504.

[18] Casini, M. A. Garulli, A. Giannitrapani, and A. Vicino, "A Remote Lab for Experiments with a Team of Mobile Robots. Sensors. 2014, 14, pp 16486-16507.

[19] Murthy, D., A. Rodriguez, and J. Lewis, "Examining the Formation of Swift Trust within a Scientific Global Virtual Team." Proceedings of the $46^{\text {th }}$ Hawaii International Conference on System Sciences, 2013.

[20] Lee, M.K., L. Takayama, “'Now, I have a Body': Uses and Social Norms for Mobile Remote Presence in the Workplace." CHI 2011 Session: Telepresence, Proceedings of the ACM Conference on Human Computer Interaction, 7-12 May, 2011 Vancouver, BC, Canada.

[21] Kiselev., A., A. Kristoffersson, A. Loutfi, "The Effect of Field of View on Social Interaction in Mobile Robotic Telepresence Systems.” March 2014.

[22] Collins, R., S.R. Hiltz., and F.P. Deek. "Knowledge Management for Learning: ICT Stem Affordances and the Impact of Order of Use." Proceedings of the $50^{\text {th }}$ Hawaii International Conference on System Sciences. 2017.

[23] Tavanapour, N., and E.A.C., Bittner. "Collaboration Among Crowdsourcees: Towards a Design Theory for Collaboration Process Design." Proceedings of the $50^{\text {th }}$ Hawaii International Conf. on System Sciences. 2017.

[24] Choi, K.S., and Y. Kim. "Easing Cross-Border Communication: MOBILE-mediated Communication and Its Framework. Proceedings of the $50^{\text {th }}$ Hawaii International Conference on System Sciences. 2017.

[25] Zhou, W., W. Yan, and X. Zhang, "Collaboration for Success in Crowdsourced Innovation Projects: Knowledge Creation, Team Diversity, and Tacit Coordination." Proceedings of the $50^{\text {th }}$ Hawaii International Conference on System Sciences. 2017.

[26] Cogburn, D.L., F. Trevisan, E. Spaniol, and M.C. Aguilar, "Building Accessible Cyberinfrastructure in the Global Disability Community: Evaluating Collaboration Readiness and Use of the DID Policy Collaboratory." Proceedings of the $50^{\text {th }}$ Hawaii International Conference on System Sciences. 2017.

[27] Fazli, F., and E. Bittner, "Cultural Influences on Collaborative Work in Software Engineering Teams. Proceedings of the $50^{\text {th }}$ Hawaii International Conference on System Sciences. 2017. 
[28] Bozan, K., "The Perceived Level of Collaborative Environment's Effect on Creative Group Problem Solving in a Virtual and Distributed Team Environment." Proceedings of the $50^{\text {th }}$ Hawaii International Conference on System Sciences. 2017.

[29] Wende, E., R. Alt., and G. King, "Towards Genuine Virtual Collaboration: Designing the Use of Mobile Remote Presence in Offshore-Outsourced Projects." Proc. of the 50 ${ }^{\text {th }}$ Hawaii Intll Conf on Sys Scie. 2017.

[30] Zhang, N., Z. Lu, Y. Shou. "Cross-Sector Collaboration and Information Integration in Local Government OneStop Services Centers: The Experiences and Lessons from a Case Study in China. Proceedings of the $50^{\text {th }}$ Hawaii International Conf on System Sciences. 2017.

[31] Cheng, X., T. Hou., S. Fu., J. Sun, "Individual Trust Development in Business Virtual Teams: An Experimental Study. Proceedings of the 50th Hawaii International Conference on System Sciences. 2017.

[32] Derrick, D.C., G.S. Ligon, E.P. Miles, L.W., Lundmark, and J.S. Elson, "Collaborative Distance: Multi-Level Analysis Framework for Recommending Collaboration Structure and Safeguards." Proceedings of the 50th Hawaii International Conf on System Sciences. 2017.

[33] Boyd., B., A. Townsley, C. Walter., C. Johnson., and R.F. Gamble, "Examining Collaboration Among Student Teams Relying on Web Applications to Coordinate Software Development. Proceedings of the 50th Hawaii International Conference on System Sciences. 2017.

[34] Fuller, R. M., and J.D. Summers, "The Impact of Virtual Team Consistency on Individual Performance and Perceptual Outcomes Over Time," Proceedings of the 50th Hawaii Int'l Conf on System Sciences. 2017.

[35] Thatcher, S., Wilson, D., and S. Brown, "(Virtual) Identity Communication: Motivation and Contextual Factors." Proceedings of the 50th Hawaii International Conference on System Sciences. 2017.

[36] Bhagwatwar, A., H. Bala., and J. Barlow. "We're In This Together: The Role of Team Characteristics in Enterprise Process Execution and Performance." Proceedings of the 50th Hawaii International Conference on System Sciences. 2017.

[37] Alammari, A., and D. Chandran, "Impact of Knowledge Sharing Adoption on Universities' Virtual Learning Communities." Proceedings of the $50^{\text {th }}$ Hawaii International Conference on System Sciences. 2017.

[38] World Bank/ World Health Organization. Global Disability Report, 2011.

[39] Paul, S. and S. Ray, "Cultural Diversity, Group Interaction, Communication Convergence, and IntraGroup Conflict in Global Virtual Teams: Findings from a Laboratory Experiment. Proceedings of the $46^{\text {th }}$ Hawaii International Conf on System Sciences. 2013.

[40] Petelin, J.B., Nelson, M.E., and J. Goodman. "Deployment and Early Experience with remotepresence Patient care in a community hospital. Proceedings of the $50^{\text {th }}$ Hawaii International Conference on System Sciences. 2017.

[41] Agarwal, R., A. W. Levinson, M. Allaf, D.V. Makarov, A. Nason, and L.M. Su, "The RoboConsultant: Telementoring and Remote Presence in the Operating Room During Minimally Invasive Urologic Surgeries
Using a Novel Mobile Robotic Interface." Urology 70 (5), 2007, pp. 970-974.

[42] Riedl, B.C., J. V. Gallenkamp, and A. Picot, "The Moderating Role of Virtuality on Trust in Leaders and the Consequences on Performance." Proceedings of the $46^{\text {th }}$ Hawaii Intl Conf on System Sciences. 2013.

[43] Rothenberg, S.S., S. Yoder, S. Kay, and T. Ponsky, "Initial Experience with Surgical Telementoring in Pediatric Laparoscopic Surgery Using Remote Presence Technology. Journal of Laparoendoscopic \& and advanced surgical techniques Volume 19, Supplement $1,2009$.

[44] United Nations. Sendai Framework for Disaster Risk Reduction 2015-2030. Third UN World Conference on Disaster Risk Reduction. 18 March 2015, Sendai, Japan.

[45] Edwards, J., "Telepresense: Virtual Reality in the Real World." IEEE Signal Processing Magazine (9) November 2011.

[46] Lewis, T., J. L. Drury, and B. Beltz., "Evaluating Mobile Remote Presence (MRP) Robots. nd.

[47] Tsui, K. M., M. Desai, H.A. Yanco, and C. Uhilik, "Telepresence Robots Roam the Halls of My Office Building." Human-Robot Interaction Workshop on Social Robotic Telepresence 2011.

[48] Väyrynen, K., and J. Aalto, “The Organization's Role in Global Virtual Team Leaders' Possibilities to Successfully Lead the Team Across Its Lifecycle." Proceedings of the $46^{\text {th }}$ Hawaii International Conference on System Sciences. 2013.

[49] Wende, E., G. Schwabe., T. Philip., and G. King, "Why They Do Not Understand: A Model of Knowledge Discourse in the Transition Phase of Globally Distributed Projects." Proceedings of the $46^{\text {th }}$ Hawaii International Conference on System Sciences. 2013.

[50] Burgard, W., P. Trahanias, D. Hähnel, M. Moors, D. Schulz, H. Baltzakis, and A. Argyros, "Tele-Presence in Populated Exhibitions Through Web-Operated Mobile Robots." Autonomous Robots 15, 299-316, 2003.

[51] United Nations General Assembly Resolution 65/186.

[52] United Nations General Assembly Resolution 64/131.

[53] United Nations General Assembly Resolution 64/154.

[54]http://www.unisdr.org/conferences/2017/globalplatfor $\mathrm{m} / \mathrm{en} / \mathrm{accessibility}$

[55] Argyris, C (2003). 'A life full of learning', Organization Studies, 24(7): 1178-92.

[56] Reason, P and Bradbury, H. (eds) (2008). The Sage Handbook of Action Research: Participative Inquiry and Practice. London.

[57] Wicks, P.G., Reason, P., Bradbury, H. (2008) "Living Inquiry: Personal, Political and Philosophical Groundings for Action Research Practice." in The Sage Handbook of Action Research, Reason, P and Bradbury, H. (eds). London, p 15-30.

[58] Interview, Craig Duncan, UNISDR. Cancun, Mexico.

[59] Interview, Stefanie Danneman, UNISDR Europe.

[60] Cogburn, D. L. "Accessible Global Governance: The Invisibility of Persons with Disabilities", UN CRPD COSP, UN Headquarters, New York, NY, 9 June 2015.

[61] Cogburn, D.L., Transnational Advocacy Networks in the Information Society: Partners or Pawns? Palgrave MacMillan, 2017 